\title{
Environmental Informatics and its Features, Functions and Stakeholders: A Comprehensive Overview
}

\author{
P.K. Paul ${ }^{1^{*}}$ and P.S. Aithal ${ }^{2}$
}

${ }^{1}$ Executive Director, MCIS, Department of CIS, Information Scientist (Offg.), Raiganj University (RGU), West Bengal, India ${ }^{2}$ Vice Chancellor, Srinivas University, Karnataka, India

*Corresponding author: pkpaul.infotech@gmail.com

Received: 18-10-2019 Revised: 22-02-2020 Accepted: 29-03-2020

\begin{abstract}
Environmental Informatics is an important interdisciplinary practicing field and rising in the recent past. It is the combination of Environmental Science and Information Science; and more clearly it is the applications of Information Technology in different aspects of Environment, Nature and Ecology. Information Technology applications are rising in different areas and environments and nature is no exception. There are numerous reasons in which Information Science or Informatics can be applied. And thus, indirectly in it applicable in other different areas viz. Geology, Geography, Climatology, Oceanography,Agriculture, Forestry,etc are also important stakeholders of Environmental Informatics. There are various places in which IT, Computing and similar technologies can be applied or task can be better, smoother and effective than the traditional systems. Apart from the traditional Computing and IT components many latest can get the benefits of Environmental Informatics. There are similar branches which are also alternatively useful in environmental management. This paper is a case study on Environmental Informatics including its features, types, role and stakeholders and functions, etc in brief.
\end{abstract}

Keywords: Environmental Informatics, IT, Computing, Environmental Sciences, Eco Friendliness, IT Management, Nature

Environment is an important concern for many purposes and the knowledge fields that care about this, is include Environment Science, Environment Studies, Environment Engineering, Environment Management, etc. And in all these subjects, Environmental Informatics are solidly applicable for its different sorts ${ }^{[1],[11]}$. In many Environmental Statistical applications also IT and Computational tools are required; therefore, Environmental Informatics is the right solution for such issues and concerns.

Environmental Informatics uses different concepts and tools of Information Technology and a few from Computer Science also ${ }^{[2],[11],[13]}$. As far as the latest tools and technologies are concerned which required in Environmental and nature related activities are included but not limited to the following-
Big Data Management.

Data Analytics.

Cloud Computing.

$\square$ Virtualization Statistical Management and Applications.

Internet of Things (IoT).

Converged Network.

Usability Engineering.

3D Graphics and Media.

User Experience Designing.

$\square$ Human Computer Interaction.

Wireless Network and Censor.

Multimedia Database.

Satellite Technology etc. 
Environmental Informatics isthus using these technologies ensuring eco friendly information systems. Based on the situation thus, different allied fields may be useful.

\section{Objective}

This paper is a case study on Environmental Informatics and allied fields and comes with the following features and functions-

To learn about the basics of Environmental Informatics including its evolution and background.

To dig out the fundamental characteristics and features of Environmental Informatics in brief.

$\square$ To find out the allied fields in which Environmental Informatics is applicable or utilizable.

To learn about the functions, role and importance of Environmental Informatics in environment, nature and the field of Environmental Sciences.

To gather information on core tools, technologies and emerging technologies responsible for information management as far as environment and nature are concerned.

To learn about the stakeholders of the Environmental Informatics and its real practice in general.

\section{Methods}

This is a conceptual paper and deals with the overview of Environmental Informatics and thus apart from secondary sources, various primary sources are used. Review of literature plays a leading role in gather Environmental Informatics related content to reach its goal to know about the basics, features, functions, role, applications of Environmental Informatics and allied field. Various websites and web portals related to the environment and ecology are also used to learn about the current scenario of applications of IT and Computing in the Environment.

\section{Environmental Informatics: Basics and Features}

Environmental Informatics is the combination of Environment (Including allied branches and subjects) and Informatics (Including allied branches and subjects). In a simple manner, it is the applications of Computing, Technologies, Informatics principles and tools in Environmental Management, Environmental Management, Sustainable Computing and Information Technology practice as well (Refer Fig: 1 for details). Environmental Informatics can be considered as following-

Applications of Information Technology and Computing in Environmental spaces.

$\square$ Applications of Environmental principles in Information Technology and Computing.

$\square$ Integration of Environment with Information Technology.

Initially, the branch Informatics was first evolved and gradually it is become a field of study and research in major countries and leading universities, worldwide. Before the development of the branch many other subjects existed viz.

\section{Function and Role of Environmental Informatics}

Environmental Informatics is required for the planning of energy, environmental and ecological systems using different tools ${ }^{[3],[3],[12]}$.

Environmental decision support including Simulation, optimization is possible with Environmental Informatics practice.

$\square$ Environmental geomatics which includes the GIS, Remote Sensing, spatial information technologies can easily useful with Environmental Informatics.

Environmental Informaticsis required for environmental chemistry and biochemistry and allied activities.

$\square$ There are different Environmental applications of functional materials in which Environmental Informatics or IT can be used.

Environmental phenomena vis. atomic, molecular and macromolecular scales,etc are possible with the Environmental IT or Environmental Informatics practice.

$\square$ Designing, Developing and modeling of chemical, biological and environmental processes are required by Environmental Informatics support.

Designing, developing and management of websites related to the environment, 
ecology, etc., became possible with the help of Environmental Informatics ${ }^{[6],[7],[15]}$.

Environmental Informatics helps in the modeling of biotechnological systems for the activities viz. enhanced pollution mitigation.

$\square$ Different multimedia tools, animation, graphics and visualization for environmental decision support systems, Ecological interface,etc can be prepared using Environmental Informatics tools.

$\square$ Different modern computational tools viz. Artificial intelligence, expert systems, machine learning, deep learning can be used for Environmental Informatics practice.

With the help of Environmental Informatics few managerial aspects viz. Environmental statistics and risk analysis become easy.

$\square$ Climate modeling, downscaling are another example of Environmental Informatics practice including the impact assessment adaptation planning,etc. ${ }^{[8],[9],[16]}$.

\section{Stakeholders in Environmental Informatics}

As far as the background of the field is concerned, it is the merging domain and fields of Environment and Informatics. Initially, the branch of Informatics started as a branch of information solutions (similar to the Information Science); using different tools and technologies. The difference of Informatics with Computer Science was, it was more application centric and concentrated on different sectors and fields. Among the initial nomenclature and branches, popular are Health Informatics, Bio Informatics and Geo Informatics and gradually other areas have been added. In recent past,Environmental Informatics has evolved as a branch of interdisciplinary in nature $^{[4],[5],[18] \text {. }}$

Hence as far as stakeholders are concerned, Environmental Informatics may be considered with the following stakeholders (also refer Fig. 1)-

Content and Information-Content is very important in better and healthy Environmental Informatics practice. As the field is concerned with the environmental oriented information activities viz. collection, selection, organization, processing, management and dissemination (of information); so that information is an important stakeholders environmental information systems, information repositories, environmental database, environmental modeling requires information and content and thus within Environmental Informatics Content and Information can be considered as vital one.

$\square$ Technologies-Technologies (also emerging technologies; refer Fig. 2) are the second most important stakeholder in Environmental Informatics and among these technology sub components of IT are important viz.

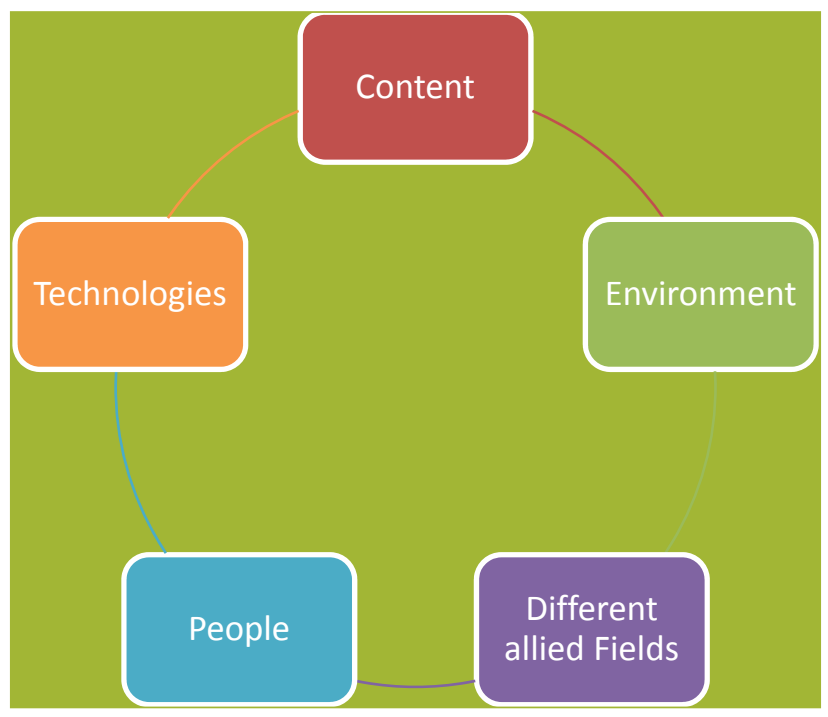

Fig. 1: Depicted the Stakeholders of Environmental Informatics

○ Software Technologies; which is required to design and develop environmental solution centric applications, programs development.

$\odot$ Networking Technologies; this is maybe required connectivity of different Environmental and Geographic station connectivity, communications of the information repositories related to the environment and ecology. Here apart from traditional networking, wireless networking, and satellite communication are treated as important ${ }^{[10],[14],,[19]}$.

$\odot$ Web Technologies; this is required for design, development of the websites and web portals related to the environment and allied areas. Thus, basic programs, tools and technologies are importantly concerned viz. HTML, DHTML, XML, Scripting Languages, Content Management Systems etc. 
$\odot$ Database Technologies; this is required for the designing and storing of information and data related to the environment, ecology and its allied field. All the Environmental Information Systems and Networks are basically connected with this type of technologies. Here Big Data Technologies and Analytics are useful as per the recent situation of data complexity in ecology and climatology.

$\odot$ Multimedia Technology; is another important component which is required to explore, disseminate information related to the environment and ecology. Here as different format viz. text, audio, video may be incorporated using various multimedia software and packages. Moreover, in Environmental Informatics different emerging multimedia allied components can be useful viz. Human Computer Interaction, Usability Engineering, User Experience Designing, etc. ${ }^{[6],[15],[20] .}$

Environment - Environment is one of the important and the things around us fall under the Environment. Moreover,there are different livings and non-living facets within Environment and all may be considered as important for Environmental Informatics. Environment is a broad interdisciplinary Science that deals with different areas of the Natural Sciences.

Users and Using Fields-Environmental Informatics is useful not only humans but also animals, forests, and all other natural resources. There are different fields which are can be treated as using fields viz.-
$\odot$ Climatology
$\odot$ Oceanography
$\odot$ Geology
$\odot$ Geography
$\odot$ Agriculture
$\odot$ Forestry etc.

\section{Academics \& Environmental Informatics}

There are different sectors and areas in which Environmental Informatics is useful and we already learned this. As far as education and training programs are concerned the core aim of such include (but not limited to the following) -

To learn about the basics of computational methods in ecology and also use of data into information towards technology.

To gain knowledge about the strategies and approaches to managing data including a large amount of data using computational analysis.

With the help of Environmental Informatics, it will be easy to develop technical skills in different methods and their applications in ecological practices.

$\square$ The Environmental Informatics programs are useful to know about the use of spatial temporal effects can affect model behavior accordingly.

$\square$ To learn about the data exploration and data mining in Environmental and ecological uses.

With the help of Environmental Informatics, the affairs such as Inference modeling, generating quantitative models on environmental aspects become easy.

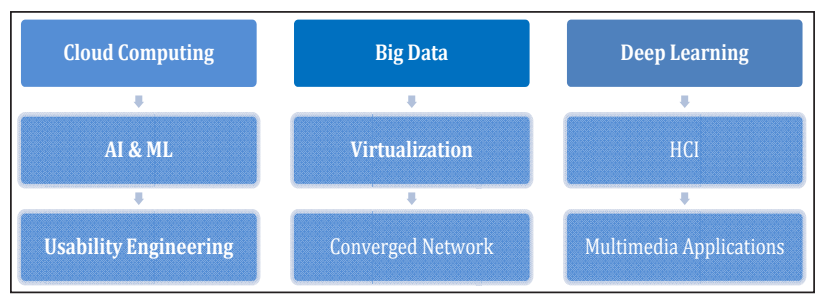

Fig. 2: Depicted different emerging technologies of Environmental Informatics

$\square$ Process, empirical including such as identifying the constraints of each model regarding the ecological things become possible with Environmental Informatics.

To learn about the use of Big Data Analytics and Data Sciences with skilled manpower in Environmental Informatics. ${ }^{[8],[17,[21]}$

$\square$ To learn about Cloud Computing, Virtualization in ecological, geo-spatial data storage utilization based on situation.

\section{CONCLUSION}

Environmental Informatics is a broad field and it is scientifically and technically well-founded education in Information Technology applications in environmental related subjects including in 
modeling, simulation, designing, development, data analysis of environment related data and also use of geographical information systems (GIS) and RS with proper technologies and also by software development. There are other areas as well which are also close and nomenclature as the field and among these few important are Environmental Information Technology, Environmental Information Systems, Geo Information Science, Geo Information Technology, etc. Due to its role, Environmental Informatics becomes useful in different sectors day by day. In Social Science also this field is emerging in the recent past. Worldwide universities have started offering a program on this emerging field of different levels as well.

\section{REFERENCES}

1. Allen, T. F., Giampietro, M. and Little, A.M. 2003. Distinguishing ecological engineering from environmental engineering. Ecological Engineering, 20(5): 389-407.

2. Argent, R.M. 2004. An overview of model integration for environmental applications - components, frameworks and semantics. Environmental Modelling E Software, 19(3): 219-234.

3. Borchardt, M., Wendt, M.H., Pereira, G.M. and Sellitto, M. A. 2011. Redesign of a component based on ecodesign practices: environmental impact and cost reduction achievements. Journal of Cleaner Production, 19(1): 49-57.

4. Cruz, F.B.D.L. and Barlaz, M.A. 2010. Estimation of waste component-specific landfill decay rates using laboratoryscale decomposition data. Environmental Science $\mathcal{E}$ Technology, 44(12): 4722-4728.

5. Haupt, S.E., Pasini, A. and Marzban, C. (Eds.). 2008. Artificial intelligence methods in the environmental sciences. Springer Science \& Business Media.

6. Hunt, C.B. and Auster, E.R. 1990. Proactive environmental management: avoiding the toxic trap. MIT Sloan Management Review, 31(2): 7.

7. Jones, D.A., Lelyveld, T.P., Mavrofidis, S.D., Kingman, S.W., and Miles, N.J. 2002. Microwave heating applications in environmental engineering - a review. Resources, Conservation and Recycling, 34(2): 75-90.

8. Laird, D.A., Yen, P.Y., Koskinen, W.C., Steinheimer, T.R. and Dowdy, R.H. 1994. Sorption of atrazine on soil clay components. Environmental Science \& Technology, 28(6): 1054-1061.

9. Maxim, L. and van der Sluijs, J.P. 2011. Quality in environmental science for policy: Assessing uncertainty as a component of policy analysis. Environmental Science E Policy, 14(4): 482-492.
10. Mykrä, H., Heino, J. and Muotka, T. 2007. Scale-related patterns in the spatial and environmental components of stream macroinvertebrate assemblage variation. Global Ecology and Biogeography, 16(2): 149-159.

11. Paul, Prantosh Kumar and Dangwal, K.L. 2014. Environmental Informatics: An Important and Possible Domain for building a Sustainable World. Journal of Chemical and Pharmaceutical Sciences, 9(4): 2759-2763.

12. Paul, Prantosh Kumar. 2013. Environment and Sustainable Development with Cloud Based Green Computing: A Case Study. Scholars Academic Journal of Biosciences (SAJB). 1(6): 337-341.

13. Paul, Prantosh Kumar, Kumar, K. and Chatterjee, D. 2013. Energy Informatics: the way for Energy and power consumed Information Systems. IEEE/IETE/CSI/DRDO Co-Sponsored 'Nationnal Conference on VLSI, Embedded System \& Communication Technology' [NCVESCOM-13], 190-192.

14. Paul, Prantosh Kumar. 2013. Energy Informatics: An Emerging and Proposed Academic Discipline for Complete Sustainable Development. Abhinav National Journal of Science and Technology, 2(4): 12-19.

15. Paul, Prantosh Kumar, Jhuma Ganguly and Ankan Sinha. 2014. Environmental Information Processing for Eco Friendly Social and Business Development -A Short Communication in National Conference on Corporate Social Responsibility: Expectations and Challenges, 258-264.

16. Paul, Prantosh Kumar, Kumar, K., Das, P., Karn, B. and Poovammal, E. 2016. Environmental Information Systems: Tools, Technologies and Other Facets Better Green World: A Brief Conceptual Study. International Journal of Recent Researches in Science, Engineering \& Technology, 4(05): 142-147.

17. Paul, Prantosh Kumar, Bhuimali, A., Ghose, M. and Chatterjee, D. 2016. Eco Informatics and Green IT as an Interdisciplinary Environmental-ComputingManagement Domain: With a Case Study of United Kingdom Programs. Palgo Journal of Education Research, 4(6): 225-229.

18. Paul, P.K. Bhuimali, A. Ghose, M., Ganguly, J. and Ghosh, M. 2017. Information Technology and Green-Eco Environment: The aspects in Interdisciplinary Scenario International Journal of Scientific Research and Modern Education (IJSRME), 2(2): 27-30.

19. Sandler, S.I. 1996. Infinite dilution activity coefficients in chemical, environmental and biochemical engineering. Fluid Phase Equilibria, 116(1-2): 343-353.

20. Thompson, S., Treweek, J.R. and Thurling, D. 1997. The ecological component of environmental impact assessment: a critical review of British environmental statements. Journal of environmental Planning and Management, 40(2): 157-172.

21. Yakhou, M. and Dorweiler, V.P. 2004. Environmental accounting: an essential component of business strategy. Business Strategy and the Environment, 13(2): 65-77. 
